Open Access

\title{
Derived signals for S \& P CNX nifty index futures
}

\author{
B. Prasanna Kumar(D)
}

\section{Correspondence:}

prasannakumar7569@yahoo.com Department of Economics,

Davangere University P. G. Centre, Guddadarangavvanhalli,

Chitradurga, Karnataka 577 502, India

\begin{abstract}
Background: The financial futures market in India is relatively new. The major advantage of derivatives as financial products is that their use minimizes the risks associated with securities. However, hedging effectiveness requires understanding key market signals such as trading margins, credit availability, and price discreteness.

Methods: This study considers the Standard \& Poor's CNX Nifty 50 Index futures for data analysis with the application of V-IGARCH $(1,1)$ two-stage model. The purpose for V-IGARCH $(1,1)$ is used to observe the positive effects of credit availability on the variance of futures returns. The first stage V-IGARCH $(1,1)$ endogenous mean and conditional variance returns are measured with exogenous factors from the second stage V-IGARCH $(1,1)$ models. The second stage V-IGARCH $(1,1)$ models specify the market participants' exogenous conditional probabilistic values for returns.
\end{abstract}

Results: In the first stage, it was observed that returns and trading margins, as well as credit availability, were cointegrated, thereby indicating a long-term relationship between them. In the first stage of the V-IGARCH $(1,1)$ model, heteroscedasticity with the mean returns through residuals was observed, where the estimated coefficients were negative. This finding indicated that maximizing returns requires efficient use of trading margins as well as availability of credit positions. From the second stage regression estimation, it was observed that trading prices and total money supply were directly related, and thus had direct effects on returns. The total money supply increased gradually until the last trading hour. In the conditional variance equation, total money supply was related negatively to the availability of credit for market participants. Under these circumstances, the efficient interbank call interest rate was necessary to maintain the trading margin. In effect, efficient Nifty returns would be achieved.

(Continued on next page) 
(Continued from previous page)

Conclusions: This study found that trading margins, credit availability, and price discreteness affect the variance of returns in the Indian futures markets. The study also found that market participation was inadequate as a result of endogenous and exogenous conditional probabilistic reasons. Efficient trading margins and effective credit availability positions were not realized. Price discreteness had a negative impact on returns, as trading prices and credit availability in each of the trading hours were inversely related. Trading risks, and hence losses, were not minimized by hedging positions. The monopoly power in the Nifty market was 8.9526. Given this monopoly power, returns were less elastic with respect to the existing trading margins, financial resources, and market microstructure (price discreteness) that were available for reinvestment. Therefore, before investing in derivatives (index futures), market investors should evaluate trading margins, credit availability positions, and price discreteness. Through these signals, investors will be able to gain essential market knowledge and participate accordingly in trading for efficient returns.

Keywords: Signals, Credit, Margin, Discreteness, Nifty, Returns

JEL classification: G10, G12, G14, G20, G32

\section{Background}

The financial futures market in India is relatively new. The major advantage of derivatives as financial products is that their use minimizes the risks associated with securities. However, hedging effectiveness requires understanding key market signals such as trading margins, credit availability, and price discreteness. These signals have significant effects on limit orders and trading returns. Usually, the futures market maintains returns in relation to the tick value. The tick value indicates the trading volume trend and thus the profit. The tick value is calculated by multiplying the tick size (the minimum price movement for a unit of a security) by the contract size, where the contract size is the multiplication of the Standard \& Poor's CNX Nifty Index Futures (hereafter "Nifty Futures" or "Nifty") price and its market lots. Therefore, the tick size and contract size influence the tick value, considering the rate of submission of limit orders. Trading margins influence the submission of limit orders, and hence the sustainability of futures trading and liquidity. Therefore, the optimal tick value is a matter of concern in derivatives trading, because the tick size (and there by price discreteness) is one of the important factor that influences the price formation in the derivatives market.

For example, Bali and Hite (1998), and Frank and Jagannathan (1998) observed that changes in share prices took place considering market frictions, such as price discreteness, that are constrained to the multiples of a tick and bid-ask bounce. They found that the stock prices generally less than the value of dividends. However, Graham et al. (2003) observed that, in spite of the decimalization of tick size, the ex-date premiums (prices to dividends) fell, and the ex-date tax-based returns, in effect, increased . Jacob and $\mathrm{Ma}(2004)$ also observed that price drops were not strictly constrained to the multiples of a tick. Price drops may be associated with a tick above or below the dividend, unlike the case of a tick below dividend shown by Bali and Hite's model. These conflicting observations on the role of market frictions can be examined in the context of the S \& P CNX Nifty Index futures market. 
The S \& P CNX Nifty Futures Index (the Nifty Futures) is the leading financial futures market in the Indian economy. India Index Services and Products Limited (IISL) owns and manages this index, which is a joint venture between the National Stock Exchange of India Limited (NSE) and the Credit Rating and Information Services of India Limited (CRISIL). "CNX" stands for CRISIL NSE INDEX. The IISL focuses on the index as a core product, for which it holds the marketing and licensing agreement with $\mathrm{S} \& \mathrm{P}$, who are world leaders in index services. The Nifty Futures is a well-diversified 50 stock index accounting for 21 sectors of the Indian economy (https://www.nseindia.com). With this vast diversification, market frictions may play a significant role in price formation for this index. It appears that the greater the tick size, the greater the returns for market participants (Barik and Supriya, 2008, 2009). Therefore, the optimal tick size and, in turn, price discreteness, sufficient trading margins, and ensuring higher credit availability for reinvestments, are all issues of concern in the context of maximization of returns.

In this context, the study presented in this paper aimed to observe and evaluate the nature and role of market participation, price discreteness with its optimality, and financial resource utilization by bank-custodian depository participants in the Nifty Futures market. The empirical results suggested that inefficient returns existed with regard to carrying and impact costs. As reflected in this study, efficient trading margins and effective credit availability positions were not realized. This finding was probably the result of exogenous conditional probabilistic values such as the following. First, lower credit availability can cause the total money supply to have a negative effect on returns. Second, the inverse relationship between the number of market lots and riskneutral trading prices during all trading hours can cause returns to be inefficient. This effect occurs because the number of market lots with index price determines the tick value in relation to the prevailing tick size, and hence the price discreteness affects returns negatively. Third, impact costs are higher during the entire time period for submission of limit orders (NSE trading hours from 09:55 IST to 15:30 IST), so there is a reduction effect on returns. Consequently, empirical examination suggested that diagnosable variables such as trading margins, credit availability, and price discreteness are decision-making market signals. Through these derived signals, investors can infer knowledge of the market and participate accordingly in financial futures trading for efficient returns.

The remainder of this paper is organized as follows. Section 2 presents a review of the literature. Section 3 presents theory along with methodology and data. Section 4 presents results and discussion. Last, study conclusions are provided in Section 5.

\section{Review of literature}

Bali and Hite (1998) predicted that a next-day stock price drop $(\Delta P)$ would be less than the dividend $(D)$, but greater than equal to the dividend minus one tick. They found that the ratio $\triangle P / D$ was significantly less than 1 , where prices were constrained to the multiples of the tick. They ran the regression of $\Delta P$ on $D$ and observed that the slope coefficient was significantly less than 1 (0.9786), where the intercept was less than zero $(-5.3753)$. This finding implied that exday prices dropped by less than the amount of dividends. They also regressed $\triangle P$ on two parts of the dividend: the integer tick portion (tick below dividend) and the fractional portion. They observed that the slope coefficient was insignificantly different from 1, the estimated intercept was less than zero 
$(-2.5208)$, and the estimated coefficient on discreteness was significantly positive (0.4531). These observations suggested that the expected price drop was about one quarter of a tick, which was below the dividend. The price drop increased by about a half-tick as the dividend approached the next higher tick multiples.

Frank and Jagannathan (1998) also ran the regression of the ex-day share price drops on dividends, where both variables were in terms of tick units. For the full sample of dividends, the portfolio regression showed that the intercept term was negative $(-2.60)$, and the slope coefficient was less than one (0.93). The empirical results from the regressions of the ex-day share price drops on both integer and fractional parts of dividends showed that estimated intercepts were significantly negative, and slopes were significantly different from 1 regardless of dividend classifications. These results clearly favor the existence of tick size effects on share prices.

Graham et al. (2003) observed that statistically the median ex-day premium declined from 0.8929 to 0.7500 , and hence the median ex-day returns $[(1-$ premium $) \times($ dividend/ cum-day price)] increased from 0.0002 to 0.0027 during the period of tick size decimalization (i.e., tick size fell from $1 / 8$ to $1 / 16$ and more decimals, where denominator values of fractions increases). The case of constant mean premium and increased mean returns also rendered similar observations. In both cases, magnitudes of bid-ask spread and tick size reductions did not have any influence on the ex-day prices anomaly.

Observing the serial correlations of residuals in the OLS model of Bali and Hite (1998), Jakob and Ma (2004) applied fixed effect panel regression of price drops on dividends and discreteness. They observed that the significant slope coefficient was always different from 1 . The estimated intercept and the estimated coefficient on discreteness were significantly different from 0 . This result implied that price drops were not strictly constrained to the multiples of a tick.

All of these studies observed conflicting results on ex-day price drops in relation to dividends, considering the importance of market frictions like price discreteness due to tick size effects and bid-ask bounces. In the present study, the tick size effect was observed through the tick value, i.e., tick size multiplied by the Nifty contract size. Contract size again depended on the number of market lots and the market lot price. Hence, tick size effect on returns was examined through the number of market lots. The time of submission of limit orders was the proxy for a bid-ask bounce effect on returns. The effects of other market frictions (e.g., trading margin, credit availability) on Nifty returns, i.e., the closing prices compared to average money values of contracts, were examined.

\section{Theory, methodology, and data}

Returns in the financial futures market are the trading-price-value ratios (TPVR), which are the day's closing prices $(D C P)$ divided by the average money values (Barik and Supriya, 2007). The average money value $(A M V)$ is the total trading value (TTV) divided by total trading quantity $(T T Q)$, i.e., the total money value of business that took place in the market during the day divided by the total number of contracts for which business took place during the day. The total money value of business that took place in the market during the day reflects the money supply at the futures market. The total number of contracts for which business took place during the day reflects the trading 
transactions at the Nifty Futures market. In other words, average money value is equal to money supply divided by transactions at the Nifty Futures market.

The quantity theory of money states that, for a given market, the total money supply $(M)$ with its velocity $(V)$ is equal to the market price times the transactions. In the case of the derivatives (futures) market, the total money supply $(M)$ is represented by the total trading volume (TTV). Here, $M$ may be narrow or broad money supply, where as $T T V$ is always a broad money as it considers broad money and portfolio management considering resource diversifications in the economy. $V$ is represented by velocity of TTV i.e., limit order submission and execution process including the call financing interest rate, tick size, tick value, bid-ask spread, margin, and so on. In other words, $V$ is equivalent to the trading volume (number of contracts traded in a given period) or open interest (number of open option contracts) of the Nifty Futures contract. $P$ is the day's closing price of the index $(D C P) . T$ is the transaction i.e., total trading quantity $(T T Q)$. Therefore, the quantity equation of the futures market is as shown:

$$
\begin{aligned}
& (M V)_{f m}=(P T)_{f m} \text { or, } \\
& T T V \times V=D C P \times T T Q \text { or, } \\
& \left(\frac{T T V}{T T Q}\right) \times V=D C P \text { or, } A M V \times V=D C P \text { or, } \\
& V=\frac{D C P}{A M V}=T P V R \text { (Trading Price Value Ratio). }
\end{aligned}
$$

Here, velocity $(V)$ varies directly with $D C P$ and inversely with $A M V$. However, closing prices are volatile in nature as the result of both systematic and unsystematic risks. One such risk is the source of call financing money for investment and reinvestment purposes. This call money depends on the call interest rate $\left(i_{t}\right)$ that determines the money supply $(T T V)$ in the futures market. Empirical testing has shown that there is a long-run relationship between Nifty Futures and spot prices, where the interbank call interest rate Granger-causes the spot price (Granger, 1969). Panda (2008) found similar results, along with other long-term and short-term interest rates, that influenced the financial markets, particularly the stock and derivatives markets. Therefore, all regionally traded interbank call interest rates, e.g., rates traded in Mumbai or Calcutta, are well related to the financial market coupon rates for 5 - 10 year government securities and for 15 - 91 day treasury bills. Therefore, call returns $(C R)$ or call-trading-price-value ratios are the Mumbai inter bank call interest rate minus the trading-price-value ratio i.e., $V=i_{t}-\left(\frac{D C P}{A M V}\right)$.

Now considering the call financing interest rate, tick size, tick value, bid-ask spread, margin, and so on, the limit order submission and execution process (velocity) is $1 / V$. This notation represents the real Nifty trading volumes (outputs) rather than the Nifty open interests, where the real call-trading-price-value ratios are calculated through nominal interbank call interest rates. This approach is taken for two reasons. First, maximum sample observations are made with actual-trading data based on trading information for executed and trading day orders. Second, according to Mankiw (2003), total output for any economy set up is equal to $M V / P=T$, or $M V=T P$, or $V=T P / M$, 
or $V=(T / M) \times P$. In the futures market, set up of the total output or real call returns $(R C R)$ is derived as shown:

$$
\begin{aligned}
& V=(T T Q / T T V) \times D C P, \text { or } \\
& V \times(T T V / T T Q)=D C P, \text { or } \\
& V \times(A M V)=D C P, \text { or } \\
& V=D C P / A M V, \text { or } \\
& 1 / V=1 /(D C P / A M V), \text { or } \\
& 1 / V=1 /\left[i_{t}-(D C P / A M V)\right], \text { or } \\
& 1 / V=1 / C R=V_{t} .
\end{aligned}
$$

That is, $V_{t}=R C R=1 / C R$

In Eq. (1), the denominator explains call returns $(C R)$ for the Nifty Futures market. Therefore, real call returns, i.e., call-velocity ( $V_{t}$, hereafter, returns) are equal to 1 divided by call-trading-price-value ratios. In day-to-day trading, if the value of $C R$ is less than 1 but positive $(0<C R<1)$, then returns will be greater than 1 . Under these circumstances, the market participants would be better off reinvesting for future profit, because the ratio of 1 to $C R$ is positive and high given the condition $0<C R<1$. Therefore, the incentive to trade rises, with consequent reinvestment and super normal profits. In contrast, if the value of $C R$ is greater than 1 , then returns will be less than 1 . In this case, market participants would not favor investment or reinvestment. In addition, if the value of $C R$ is equal to 1 , then returns will be equal to one. Under this circumstance, incentive for business as well as transaction motives would be in balanced form for future investment at day-to-day normal profit.

However, returns $\left(V_{t}\right)$ depend on trading margins, tick values considering tick size, and the traded number of market lots -and thus on price discreteness and credit availability for market participants. In the context of empirical examination, these frictions are market signals, where this study developed model by following the models of Bollerslev (1986, 1987), Bollerslev et al. (1988), as well as the two-stage GARCH model of Hiraki et al. (1995), and the two-stage IGARCH model of Barik and Supriya (2007).The dependent variables for this study are returns $\left(V_{t}\right)$, total money supply $\left(M_{3 t}\right)$, number of market lots $\left(M_{l t}\right)$, and impact costs $\left(C_{t}\right)$. The independent variables are trading margins $\left(M_{t}\right)$, and trading prices $\left(T_{p t}\right)$, among others. The trading price is the equilibrium price determined by the market, where the risk-free financing rate is the interbank call interest rate. Therefore, in the futures trading mechanism, this equilibrium trading price is the risk-neutral and reference price. The assumption is that by the last hour of trading (i.e., 15:30 IST), informed market participants have achieved symmetry and have available perfect market information, where volatile and chaotic trading does not exist.

For this study, the integrated generalized autoregressive conditionally heteroskedastic (V-IGARCH) model specifications are $\widehat{\alpha}_{0}>0, \widehat{\alpha}_{1} \geq 0, \widehat{\alpha}_{2} \geq 0, \widehat{\alpha}_{3} \geq 0$, and $\widehat{\alpha}_{1}+\widehat{\alpha}_{2}=1$. After several rigorous empirical estimations through the standard GARCH model, results showed that the specification $\widehat{\alpha}_{1}+\widehat{\alpha}_{2}<1$ does not hold for the Indian derivatives market. Previous studies, as well as the study presented in this paper, have observed this result. 
Therefore, this study uses the V-IGARCH $(1,1)$ model, where the conditional variance $\left(h_{t}=\widehat{\sigma}_{t}^{2}\right)$ equation follows $\widehat{\alpha}_{1}+\widehat{\alpha}_{2}=1$. A lag weight of 1 for credit availability is included as an independent variable for variance returns. The purpose for V-IGARCH $(1,1)$ is used to observe the positive effects of credit availability on the variance of futures returns. Therefore, the first stage of the V-IGARCH $(1,1)$ model is given as shown:

$$
\begin{aligned}
& V_{t}=\widehat{\beta}_{0}+\widehat{\beta}_{1} M_{t}+\widehat{\beta}_{2} w_{t}+u_{t} \\
& h_{t}=\widehat{\alpha}_{0}+\widehat{\alpha}_{1} \widehat{u}_{t-1}^{2}+\widehat{\alpha}_{2} h_{t-1}+\widehat{\alpha}_{3} w_{t-1}^{2}
\end{aligned}
$$

where, $u_{t}=\widehat{\sigma}_{t} v_{t}=\sqrt{h}_{t} v_{t}$, and $v_{t}$ is an i.i.d sequence $\sim(0,1)$. Equation (2) contains both the mean and variance returns. Here, $V_{t}$ represents the dependent variable, and $M_{t}$. and $w_{t}$ are independent variables. However, maintenance of the trading margin depends on the interbank call interest rate i.e., the financing interest rate, which again depends on daily trading volumes in the call money market. This mechanism also relies on total money supply or broad money $\left(M_{3 t}\right)$, which is equal to time deposits plus narrow money $\left(M_{1 t}\right)$. Therefore, broad money ultimately determines the financial resources for Nifty trading through the maintenance of trading margins that heavily depend on the interbank call interest rate. However, this financing rate is the equilibrium rate based on demand for, and supply of, call money trading volumes, which depend, in turn, on the availability and sufficient level of deposits, such as time deposits and narrow money.

Market theory states that if total money supply decreases (or increases) then money supply in call market also decreases (or increases) because of restricted (or unrestricted) money flow to the financial institutions and banks. In contrast, the call money volume decreases or increases when the interbank call interest rate increases or decreases with the existing demand for call money. Suppose the interbank call interest rate increases. In this scenario, investors would not seek financial resources from this call market, given the risk of loss at the existing demand level for call money. Consequently, the financial resources for investments in futures instruments would decrease. In contrast, suppose the interbank call interest rate decreases. Under this circumstance, investors would want financial resources from this call market because of the value of reinvesting at the existing demand level for call money. Thus, increased investment would take place in the futures market.

In this context, it is observed that if there is a regressing interbank call interest rate on $M_{3 t}$ with the model of $\ln \left(i_{t}\right)=\hat{\theta}_{0}+\hat{\theta}_{1} \ln \left(M_{3 t}\right)+\eta_{t}$, then $\mathrm{R}^{2}$ is 0.5 and $\hat{\theta}_{1}$ is significantly negative. This result implies that there is an inverse relationship between the interbank call interest rate and broad money. In the case of an increasing interbank call interest rate, investors will not desire financial resources from this call market, if there will be a relatively constant demand for call money that costs more to investors during recession or even saturation business cycles. Even in the case of changing demand for call money, the same equilibrium theory holds, where after some period the total money supply is constant. Yuan (2005) observed that the borrowing constraint and information asymmetry cause confusion, crises, and contagion in stock prices. Yuan 
(2005) suggested rectification of liquidity crises through government intervention that would reduce the borrowing constraint and information asymmetry on trading.

Therefore, the interbank call interest rate should decrease with the increasing total money supply in the economy. This implies that lending to banks, depository participants, and other financial institutions would increase. Since trading margins have a direct relationship with the call interest rate, this financing rate should be at an appropriate level. In turn, resource availability for reinvestment in Nifty Futures trading will exist. Here, if banks have low cost lenders, then the supply of credit to borrowers (investors) would hold well (Black and Strahan, 2002; Tassel, 2002). Therefore, in financial markets, the call interest rate should be at an appropriate level for resource generation, diversification, and utilization.

In eq. (2), independent dummy variable $w_{t}$ is included to measure the credit availability position of the market. If credit availability for investment exists, then, $w_{t}=1$, otherwise $w_{t}=0$. Hence, in the model, the mean value of credit availability position of the market is $E\left(V_{t} \mid M_{t}, w_{t}=1\right)=\left(\widehat{\beta}_{0}+\widehat{\beta}_{2}\right)+\widehat{\beta}_{1}\left(M_{t}\right)$. Alternatively, the mean value of credit unavailability position of the market is $E\left(V_{t} \mid M_{t}, w_{t}=0\right)=\widehat{\beta}_{0}+\widehat{\beta}_{1}\left(M_{t}\right)$ (Barik and Supriya, 2007). Theory suggests that credit or lending in the economy should be at an appropriate level for best use of money supply. In this case, conditional variance considers the positive impact of this credit availability situation. Therefore, $h_{t}$ depends on $w_{t-1}^{2}$, which is an independent variable. Since $w_{t-1}^{2}$ is positive, it is expected that the value of $\widehat{\alpha}_{3}$ will be zero. In these situations, if the expected mean and conditional variance values are realized with a higher significance level, then there is a logical reason to measure and evaluate the level of realization in relation to market making. Therefore, first stage V-IGARCH $(1,1)$ endogenous mean and conditional variance returns are measured with exogenous factors from the following second stage V-IGARCH $(1,1)$ models:

$$
\begin{aligned}
& M_{3 t}=\hat{\gamma}_{01}+\hat{\gamma}_{11} \Delta \widehat{u}_{t-1}+\hat{\gamma}_{21} \Delta \widehat{u}_{t-2}+\hat{\gamma}_{31} \Delta w_{t-1}+\hat{\gamma}_{41} T_{p t}+\hat{\gamma}_{51} \sum_{i=1}^{3} D_{i}+\varepsilon_{m 3 t} \\
& h_{1 t}=\hat{\delta}_{01}+\hat{\delta}_{11} \hat{\varepsilon}_{m 3 t-1}^{2}+\hat{\delta}_{21} h_{1 t-1}+\hat{\delta}_{31} \Delta w_{t-1}^{2} \\
& M_{l t}=\hat{\gamma}_{02}+\hat{\gamma}_{12} \Delta \widehat{u}_{t-1}+\hat{\gamma}_{22} \Delta \widehat{u}_{t-2}+\hat{\gamma}_{32} \Delta w_{t-1}+\hat{\gamma}_{42} T_{p t}+\hat{\gamma}_{52} \sum_{i=1}^{3} D_{i}+\varepsilon_{m l t} \\
& h_{2 t}=\hat{\delta}_{02}+\hat{\delta}_{12} \hat{\varepsilon}_{m l t-1}^{2}+\hat{\delta}_{22} h_{2 t-1}+\hat{\delta}_{32} \Delta w_{t-1}^{2} \\
& C_{t}=\hat{\gamma}_{03}+\hat{\gamma}_{13} \Delta \widehat{u}_{t-1}+\hat{\gamma}_{23} \Delta \widehat{u}_{t-2}+\hat{\gamma}_{33} \Delta w_{t-1}+\hat{\gamma}_{43} T_{p t}+\hat{\gamma}_{53} \sum_{i=1}^{3} D_{i}+\varepsilon_{c t} \\
& h_{3 t}=\hat{\delta}_{03}+\hat{\delta}_{13} \hat{\varepsilon}_{c t-1}^{2}+\hat{\delta}_{23} h_{1 t-1}+\hat{\delta}_{33} \Delta w_{t-1}^{2}
\end{aligned}
$$

Equations (3), (4), and (5) specify the market participants' exogenous conditional probabilistic values for returns. These second stage models incorporate in dependent variables such as the total money supply, number of market lots (i.e., the market depth 
of futures trading), and impact costs. These factors are included because returns depend on broad money through the call-money volumes. In this case, the inter bank call interest rate is the significant factor that determines financial resources for investments in the derivatives market. These second stage models incorporate independent variables such as $\Delta \widehat{u}_{t-1}=\widehat{u}_{t}-\widehat{u}_{t-1}, \Delta \widehat{u}_{t-2}=\widehat{u}_{t}-\widehat{u}_{t-2}, \Delta w_{t-1}=w_{t}-w_{t-1}$, and $\Delta w_{t-1}^{2}=\left(w_{t}-w_{t-1}\right)^{2}$, both in mean and variance equations respectively. These independent variables are derived from the first stage model.

Equation (3) explains the market determined equilibrium-trading price that provides incentives to borrow for investment purposes. In other words, the efficient utilization of borrowing or lending is realized through this independent reference equilibrium-trading price i.e., market-determined risk-neutral last trading price $\left(T_{p t}\right)$.

Equation (4) explains the impact of the number of market lots and, thereby, the influence of tick value and price discreteness on Nifty returns. The independent variables are $T_{p t}, \Delta \widehat{u}_{t-1}, \Delta \widehat{u}_{t-2}, \Delta w_{t-1}$, and $\Delta w_{t-1}^{2}$. Independent variables such as $D_{i}, \Delta w_{t-1}, \Delta \widehat{u}_{t-2}$, and $\Delta \widehat{u}_{t-1}$ determine the appropriate $M_{l t}$, which determines either short or long Nifty hedging positions. Therefore, efficient hedging with the reduction of both systematic and unsystematic risks is expected in this market. The second stage model also establishes the relationship between impact costs and risk-neutral last trading prices (Equation 5), because daily risk-neutral trading prices motivate the reduction of losses and ensure profitable returns.

In these second stage mean equations, the time (trading hours) of submission of limit orders is incorporated using dummy variables $D_{1}, D_{2}$, and $D_{3}$ in order to examine the impact of each of these variables on the availability and reliability of financial resources. These resources include borrowing from banks and financial institutions or lending to market participants. Also included are the number of market lots that direct hedging considering price discreteness, which impacts costs and returns. Therefore, these second stage V-IGARCH $(1,1)$ models measure and evaluate the exogenous conditional probabilistic values for the first stage returns $\left(V_{t}\right)$.

In eqs. (3), (4), and (5), estimators in mean equations are used as follows:

- Estimators $\hat{\gamma}_{01}, \hat{\gamma}_{02}$, and $\hat{\gamma}_{03}$ measure the percentage change in total money supply, number of market lots, and impact costs for a given percentage change in other exogenous factors such as non-trading hours.

- Estimators $\hat{\gamma}_{11}, \hat{\gamma}_{21}, \hat{\gamma}_{12}, \hat{\gamma}_{22}, \hat{\gamma}_{13}$, and $\hat{\gamma}_{23}$ measure the percentage change in total money supply, number of market lots, and impact costs for a percentage change in other exogenous miscellaneous factors derived from the first stage estimation.

- Estimators $\hat{\gamma}_{31}, \hat{\gamma}_{32}$, and $\hat{\gamma}_{33}$ measure the percentage change in total money supply, number of market lots, and impact costs for a percentage change in other exogenous factors involved with credit availability.

- Estimators $\hat{\gamma}_{41}, \hat{\gamma}_{42}$, and $\hat{\gamma}_{43}$ measure the percentage change in total money supply, number of market lots, and impact costs for a percentage change in risk-neutral trading prices. 
- Estimators $\hat{\gamma}_{511}, \hat{\gamma}_{512}, \hat{\gamma}_{513}, \hat{\gamma}_{521}, \hat{\gamma}_{522}, \hat{\gamma}_{523}, \hat{\gamma}_{531}, \hat{\gamma}_{532}$, and $\hat{\gamma}_{533}$ measure the percentage change in total money supply, number of market lots, and impact costs for a percentage change in time of submission of limit orders.

All of these estimates affect Nifty trading returns. In addition, second stage variance equations explain the impacts of positive independent credit availability with $\mathrm{V}$ IGARCH $(1,1)$ model specification.

In this study, variables used logarithmic transformations, and the initial OLS estimation led to the maximum likelihood estimation. Equations (2), (3), (4), and (5) measured both endogenous and exogenous conditional probabilistic values for market participants with the study's sample period. Therefore, this study established empirically the null-hypothesis that trading margins, credit availability, and price discreteness did not affect the variance of returns in the Indian futures market. However, futures trading motives take into consideration the above independent factors as the market makers inherit, generate, initiate, and realize them. In this context, the following data descriptions and empirical results were driving forces to realize the study's objective to observe and evaluate the nature and role of market participation, role of price discreteness with its optimality, and financial resource utilization by the bank-custodian depository participants for nifty futures market.

The NSE provided the derivatives segment data. This study used daily data consisting of 506 observations from December 02, 2002 to November 30, 2004 with maximum trace. Returns $\left(V_{t}\right)$ were calculated with defining variables DCP, TTQ, TTV and $i_{t}$, where data on the variable $i_{t}$ were collected from the Reserve Bank of India (RBI) website. From the NSE derivatives segment data, the total number of trades that took place on the Nifty Futures instrument during the trading day was considered to be the proxy for the trading margin $\left(M_{t}\right)$ for two reasons. First, the NSE does not have the ready-made data required for the research. Second, since the rules of derivatives trading require sufficient trading margin for order execution, if the initial margin requirement is not there, then a particular trade will not take place. Therefore, the assumption is that only those participants who have a sufficient balance in their margin accounts along with their initial margin can trade. The variable "total number of trades that took place on FUTIDX during the trading day" reflects this assumption. Therefore, this variable was considered to be a proxy for trading margin $\left(M_{t}\right)$.

Nifty futures contracts expire on the last Thursday of each month. Usually, new contracts with a three-month expiry (expiration) are traded on the Friday following the last Thursday. Therefore, Thursday was the day of the week represented as the contract expiration date in effect on returns. In this context, Barik and Supriya (2005) observed that there is a "Thursday Effect" on Nifty trading. Badhani (2007) found that for derivatives contracts, there is a significant expiration-day effect on prices and trading volumes. The trading volumes increase before and on the expiration-day with increased selling pressure from the arbitrageurs who liquidate their positions. This creates a falling price situation. After the expiration day, these trading volumes decrease and prices increase. In addition, a complete three-month Nifty Futures contract might include 13 Thursdays, which is a matter of concern when making decisions to hold the Nifty Futures at a particular market position, because of variability and instability in the securities market. Therefore, in this study period, the expiry Thursdays were assigned a 
dummy value of 1 , and a value of 0 otherwise. These dummy values were considered to be proxies for credit availabilities $\left(w_{t}\right)$, because without these proxies for financial resources, futures contracts would expire before their contract periods, or reinvestments would be difficult, all of which would affect liquidity in the market.

Total money supply or broad money $\left(M_{3 t}\right)$ data were collected from the RBI website, and were available in monthly form. These data were considered to be proxies for daily data. For example, in December, 2002, the broad money amount was 1682, 942 INR. Then each of trading day since December, 2002 was calculated based on 1682, 942 INR and other successive values. In this way, monthly broad money data were used as daily data for the respective trading month.

Let the betas for each of the traded securities in NSE be 1. During the study period, the market lot on the Nifty Futures was 200. This study assumed that Nifty contract size was at its base value, i.e., $1000 \times 200=200,000$ INR. Assume that the total money value of the business in a particular Nifty trading day reflected the total money supply for seller, who used to buy Nifty Futures. Here, Nifty market lots were sold or bought with short or long securities positions in futures market. Accordingly, returns in terms of profit or loss were determined based on the market positions and market sentiments as reflected in movements of the Nifty index. Thus, the impact of the number of Nifty market lots traded for hedging purposes had a significant effect on $V t$.

We know that the tick value $=$ tick size $\times$ contract size. Throughout this study period, tick size was constant at 0.05 . Contract size was equal to the price multiplied by the market lot, which was determined by the NSE. In this case, appropriate lot size, and hence the number of market lots that were traded, determined the appropriate tickvalue-size ratios (Nifty price $\times$ lot size $=$ tick value/tick size. This tick-value-size ratio determined returns according to the movement of Nifty prices in terms of profit or loss. Therefore, the calculation for the number of the Nifty market lots or contract size at base price was the total money value of the Nifty business divided by the value of one Nifty market lot at Nifty base price. Note, please, that the NSE Nifty market lot was revised to 50 in February 06, 2007, and there after the market lot 50 was used for trading. However, during this study period, one market lot was 200. Therefore, 506 daily observations for $M_{l t}$ were calculated based on a market lot of 200 . Then in the second stage, the impact of the tick-value-size ratio on returns was analyzed.

Monthly impact cost $\left(C_{t}\right)$ data were collected from the NSE website. These were considered to be proxies for daily data. For example, in December, 2002, the impact cost was 0.09. Then each of the trading day since December, 2002, was evaluated using the proxy of 0.09 and other successive figures. In this way, monthly Nifty impact cost data were used as daily data for the respective trading month. The risk-neutral trading price $\left(T_{p t}\right)$ data were extracted from the derivatives segment data provided by the NSE.

For the term of this study from December 02, 2002, to November 30, 2004, the first $1 / 3$ of the daily study period was considered to be morning hours trading (from 09:55 IST to $11: 47$ IST), which totaled about $111.67 \mathrm{~min}$. The second $1 / 3$ of the daily study period, between the initial and last periods of Nifty Futures trading, was considered to be mid-hours trading (from 11:47 IST to 13:39 IST), which totaled about $111.67 \mathrm{~min}$. The last period of Nifty Futures trading, i.e., the remaining $1 / 3$ of the daily study period, was considered to be the last hours of trading (from 13:39 IST to 15:30 IST), which ran for about $111.67 \mathrm{~min}$ also. 
The initial period of trading was more active, and the market experienced large limit order submissions during the morning trading hours. Therefore, the assumption was that as the daily market matures, i.e., moves from one daily period to another trading hours, the frequency of submission of limit orders will vary. Over the course of time, perfect and symmetric information can be accessed. In addition, non-trading hours may exhibit sufficient reasons to make the market volatile and asymmetric during the next usual trading day i.e., from 09:55 IST to 15:30 IST. Accordingly, the availability and reliability of financial resources, the number of market lots that hedge the risks considering impact costs, and trading returns can be evaluated.

Accordingly, to examine the impact of the time of submission of limit orders using the dummy variables, each one third of the study period was assigned a value of 1 or 0 . $D_{1}$ was equal to 1 if the initial period of Nifty Futures trading (first $1 / 3$ of the trading day) was considered to be morning hours trading (from 09:55 IST to 11:47 IST), and 0 otherwise. $D_{2}$ was equal to 1 if it fell between the initial and last periods of Nifty Futures trading (second $1 / 3$ of the trading day), and 0 otherwise. $D_{3}$ was equal to 1 if it fell during the last period of Nifty Futures trading (remaining $1 / 3$ of the trading day), and 0 otherwise.

\section{Results and discussion}

While presenting V-IGARCH $(1,1)$ estimation results, there was a need to examine the long-run cointegration relationship between $V_{t}$ and $M_{t}$, as well as $w_{t}$. In this case, the Engle and Granger (1987) two-step cointegrating and error correction model was applied:

$$
\begin{aligned}
& \boldsymbol{V}_{\boldsymbol{t}}=\widehat{\boldsymbol{\beta}}_{0}+\widehat{\boldsymbol{\beta}}_{1} \boldsymbol{M}_{\boldsymbol{t}}+\widehat{\boldsymbol{\beta}}_{2} \boldsymbol{w}_{\boldsymbol{t}}+\boldsymbol{u}_{\boldsymbol{t}} \\
& \Delta V_{t}=\widehat{\lambda}_{0}+\widehat{\lambda}_{1} \widehat{u}_{t-1}+\widehat{\lambda}_{2} \Delta M_{t}+\widehat{\lambda}_{3} \Delta w_{t}+v_{t}
\end{aligned}
$$

where, $\Delta V_{t}=V_{t}-V_{t-1}, \Delta M_{t}=M_{t}-M_{t-1}, \Delta w_{t}=w_{t}-w_{t-1}$, and $\widehat{\lambda}_{1} \widehat{u}_{t-1}=$ error correction term. With the unrestricted $\Delta \widehat{u}_{t}=\hat{c}_{0}+\hat{c}_{1} t+\hat{c}_{2} \widehat{u}_{t-1}+\hat{c}_{3} \Delta \widehat{u}_{t-1}+e$ and the restricted $\Delta \widehat{u}_{t}=\hat{c}_{0}+\hat{c}_{3} \Delta \widehat{u}_{t-1}+e$ residual regressions, it was estimated that the computed $\mathrm{F}$ ratio was 38.62 . This value was greater than the DF critical value 8.34 at the $1 \%$ level with the restriction of $\hat{c}_{0}, \hat{c}_{1}=0$, and $\hat{c}_{2}=0$, where $\hat{c}_{2}=\rho-1$ and $\rho=1$ (Dickey and Fuller, 1981). Therefore, this study rejected the residual random walk hypothesis at the $1 \%$ level. Again, the DF test on estimated residuals with a constant and trend showed that the absolute estimated value $|-12.05|$ was greater than the DF absolute critical value $|-3.98|$ at the $1 \%$ level (Table 1 ).

Table 1 Cointegration test

\begin{tabular}{lc}
\hline EstimatedRegression & Estimates \\
$V_{t}=\widehat{\beta_{0}}+\widehat{\beta_{1} M_{t}+\widehat{\beta_{2}} w_{t}+u_{t}}$ & $-2.5480^{*}$ \\
$\widehat{\beta_{0}}$ & $0.1369^{*}$ \\
$\widehat{\beta_{1}}$ & $-0.0094^{* *}$ \\
$\widehat{\beta_{2}}$ & 38.6198 \\
$F$ ratio test statistic & -12.0479 \\
DF test statistic on residuals &
\end{tabular}

Note:* $\left.{ }^{* *}\right)$ Significant at $0.01(<0.01)$ level. $V_{t}=$ returns, $M_{t}=$ trading margins, and $w_{t}=$ credit availability dummy variable. The result shows the cointegration between returns and trading margin with credit availability holds good 
In addition, the study estimated that from the model $\Delta \widehat{u}_{t}=\hat{c}_{0}+\hat{c}_{1} t+\hat{c}_{2} \widehat{u}_{t-1}+\hat{c}_{3}$ $\sum_{j=1}^{p} \Delta \widehat{u}_{t-j}+e$ for $\mathrm{j}=1$, the estimator ' $\hat{c}_{2}$ ' is negative (-0.3663) at 0.01 level, where the estimated absolute tau value was greater than the absolute DF critical value i.e., $|-8.79|>|-3.98|$ or $-8.79<-3.98$ at the $1 \%$ level (Augmented Dickey-Fuller test; Prasanna Kumar, 2011). These results proved that $\widehat{u}_{t}$ was stationary with $\mathrm{I}(0)$.

Once again, the results showed that the cointegrating regression Durbin-Watson $(d)$ test value was greater than 0.5 , which rejected the null of unit root in the errors at the $1 \%$ level. From these results, it was concluded that $V_{t}$, and $M_{t}$, as well as $w_{t}$, were cointegrated. Thus, the cointegration between returns and trading margins with credit availability held good. Empirically, it was also shown that other variables in second stage V-IGARCH(1,1) models were stationary.

From Table 2, it can be seen that estimator $\widehat{\lambda}_{0}$ had a lower positive value and was approaching zero. The estimated coefficient $\widehat{\lambda}_{1}$ was negative. This implied that an imbalance between returns and trading margins with credit availability during one period was corrected in the next period at about $0.4132 \%$ for long-run equilibrium. Thus, this result indicated that the long run cointegration between returns and the trading margin with credit availability held good.

The estimated coefficient $\widehat{\lambda}_{2}$ was positive. This suggested that if the trading margins increased by $1 \%$, on average, returns would increase by about $0.0187 \%$. The estimated coefficient $\widehat{\lambda}_{3}$ was negative, suggesting that there was an inverse relationship between returns and credit availability. Therefore, it appeared that there was need for an appropriate lending policy that would satisfy the existing higher margin requirements in relation to returns. To achieve equilibrium and stable returns, balanced and sustainable credit availability would be necessary, along with an appropriate level of trading margin for the market participants. These initial linear estimation results led to the efficient maximum likelihood estimation results.

Table 1 and Table 2 demonstrate that the error term $\left(u_{t}\right)$ was stationary in nature, where variables such as $V_{t}$, and $M_{t}$, as well as $w_{t}$, were cointegrated with long-run equilibrium adjustments (Equation 6). Therefore, considering this stationary $\widehat{u}_{t}$, the VIGARCH $(1,1)$ model was applied for this study.

From Table 3 , it can be observed that the significant estimator $\widehat{\beta}_{0}$ was negative. This result implied that if other factors such as impact and carrying costs rise by $1 \%$, on average, returns will change by about $-2.2663 \%$. This finding again implies that in the presence of trading margins, returns would not increase positively with impact or carrying costs, or with some other costs. In other words, returns were lower with the

Table 2 Estimated error correction model

\begin{tabular}{lc}
\hline Error correction model & Estimates \\
$\Delta V_{t}=\widehat{\lambda}_{0}+\widehat{\lambda}_{1} \widehat{U}_{t-1}+\widehat{\lambda}_{2} \Delta M_{t}+\widehat{\lambda}_{3} \Delta w_{t}+v_{t}$ & \\
$\widehat{\lambda}_{0}$ & 0.0001 \\
$\hat{\lambda}_{1}$ & $-0.4132^{*}$ \\
$\widehat{\lambda}_{2}$ & $0.0187^{* *}$ \\
$\widehat{\lambda}_{3}$ & $-0.0058^{* *}$ \\
\hline $\begin{array}{l}\left.\text { Note: }{ }^{* * *}\right) \text { Significant at } 0.01(<0.01) \text { level. } \Delta V_{t}=V_{t}-V_{t-1}, \Delta M_{t}=M_{t}-M_{t-1} \text {, and } \Delta w_{t}=w_{t}-w_{t-1} . \text { The result indicates that } \\
\text { the long run cointegration between returns and trading margin with credit availability holds well }\end{array}$
\end{tabular}


Table 3 First stage V-IGARCH $(1,1)$ regression model (Equation 2)

\begin{tabular}{ll}
\hline Estimators & Estimates \\
$\widehat{\beta_{0}}$ & $-2.2663^{*}$ \\
$\widehat{\beta_{1}}$ & $(0.0000)$ \\
$\widehat{\beta_{2}}$ & $-0.1117^{*}$ \\
& $(0.0000)$ \\
$\widehat{a_{0}}$ & $-0.0037^{* *}$ \\
$\widehat{a_{1}}$ & $(0.3800)$ \\
$\widehat{a_{2}}$ & $0.0079^{*}$ \\
& $(0.0000)$ \\
$\widehat{a_{3}}$ & $0.9556^{*}$ \\
& $(0.0000)$ \\
Log-Likelihood & $0.0444^{* *}$ \\
Skewness & $(0.2130)$ \\
Kurtosis & $0.0087^{*}$ \\
\hline
\end{tabular}

Note:* $\left.{ }^{* *}\right)$ Significant at $0.01(<0.01)$ level. ${ }^{\dagger}$ Significant at 0.01 level. The first stage V-IGARCH $(1,1)$ estimation considers NSE daily data from December 02, 2002, to November 30, 2004. Mean and conditional variance equations are, $V_{t}=\widehat{\beta}_{0}+\widehat{\beta}_{1} M_{t}+\widehat{\beta}_{2} w_{t}+u_{t}$ $h_{t}=\widehat{a}_{0}+\widehat{a}_{1} \widehat{u}_{t-1}^{2}+\widehat{a}_{2} h_{t-1}+\widehat{a}_{3} w_{t-1}^{2}$

where, $V_{t}=$ returns, $M_{t .}=$ trading margins, and $w_{t}=$ credit availability dummy variable. The results indicate that inefficient returns exist with the existing inefficient trading margins and ineffective credit availability positions. The non-realization of returns is due to conditional probabilistic values, which are explained in second stage V-IGARCH $(1,1)$ estimations. Here, the conditional variance is $1.02\left(\widehat{a}_{0}+\widehat{a}_{1}+\widehat{a}_{2}+\widehat{a}_{3}\right)$, where Nifty variance returns are negative at around -1.20 (Fig. 1c)

existence of these costs. In this case, carrying cost implied the difference between financing cost (interest cost) of a portfolio that purchased the underlying Nifty Index futures, and the present value of dividends from stocks in the Nifty Index portfolio. Considering this carrying cost, the futures price was determined by the relationship between the basis and the day's closing price.

Impact cost was the cost of a stock transaction for a specified and predetermined order size, where the percentage change was experienced with reference to the ideal price: [(best buy order + best sell order) / 2]. Other costs were miscellaneous costs in Nifty Futures trading. Therefore, the estimated coefficient $\widehat{\beta_{0}}$ demonstrated that if the trading margin and credit availability variables were kept as zero or negative values, returns changed negatively with the existence of these costs (carrying costs + impact costs + other costs).

The significant estimated slope coefficients $\widehat{\beta_{1}}$ and $\widehat{\beta_{2}}$ were negative (i.e., -0.1117 and -0.0037 respectively). This finding demonstrated that the estimated slope coefficient $\widehat{\beta_{2}}$ was negatively related to $V_{t}$ for the study period at appropriate significance levels. Here, the study rejected the null hypothesis of equal mean value of credit availability. These results indicated that credit availability was restricted, where trading margins were inversely related with returns. These results also showed that the conditional probabilistic beliefs for returns were negatively related with trading margins through the negative coefficient of the credit availability dummy variable.

In addition, Table 3 shows that estimator $\widehat{\alpha}_{0}$ was 0.0079 , with its variations ranging from 0.00 to 0.51 over the sample period (Fig. 1b, Table 3 ), where the estimated conditional 


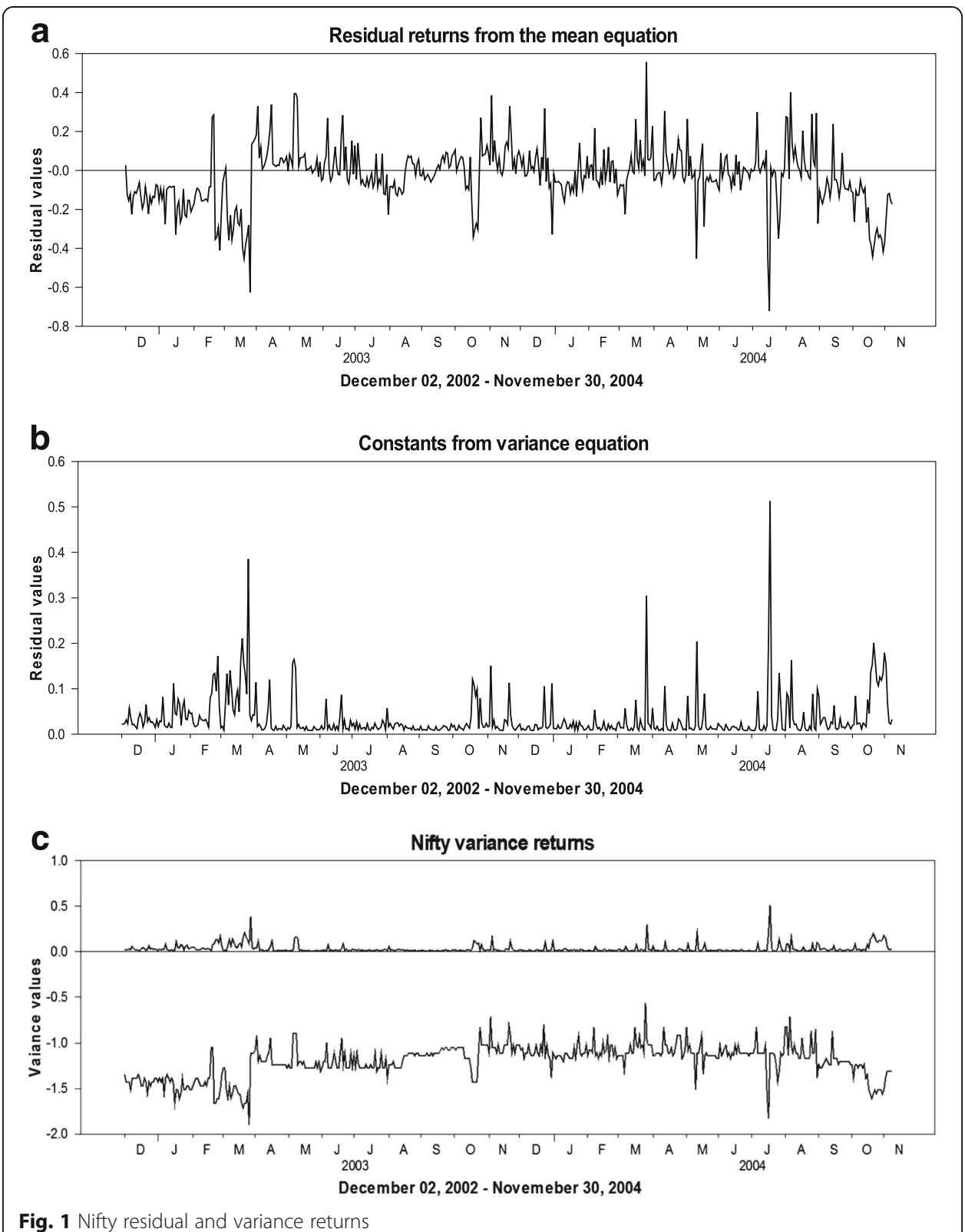

Fig. 1 Nifty residual and variance returns

variance was $1.02\left(\widehat{\alpha_{0}}+\widehat{\alpha_{1}}+\widehat{\alpha_{2}}+\widehat{\alpha_{3}}\right)$. However, Nifty variance returns $\left(h_{t}\right)$ ranged from -1.90 to -0.56 (Fig. 1c). Based on this last observation, it was also shown that the one-step forecasted Nifty variance returns were -1.14 . Therefore, these results explained inefficient valuation in the Indian futures market.

Hence, from first-stage V-IGARCH $(1,1)$, the results proved that credit availability positions were not realized with endogenous conditional probabilistic values for the market participants. The reasons for negative returns and low estimated coefficients in first-stage mean equations were explained in second stage V-IGARCH $(1,1)$ models. In the second stage models, $M_{3 t}, M_{l t}$, and $C_{t}$ were used as dependent variables and $\Delta \widehat{u}_{t-1}$, $\Delta \widehat{u}_{t-2}, \Delta w_{t-1}, T_{p t}$, and $D_{i}$ were used as independent variables, where the estimated 
coefficients were explained as exogenous conditional probabilistic values for nonrealization of trading margins and credit availability, and therefore, for returns.

Table 4 shows that significant estimators such as $\widehat{\gamma}_{511}, \widehat{\gamma}_{512}$, and $\widehat{\gamma}_{513}$ were positive. This finding implied that if the trading hours increased by $1 \%$ of each $1 / 3$ of the total trading time-period, on average, the total money supply would increase by about $0.1289 \%$, $0.1299 \%$, and $0.2368 \%$ respectively. This outcome made clear that an increase in money supply would have a significant effect on first stage returns across all trading hours (i.e., 09:55 IST to 15:30 IST). Therefore, the significant estimator $\widehat{\gamma}_{41}$ was positive, implying that if the risk-neutral trading price rises by $1 \%$, on average, the total money supply will rise by about $0.1202 \%$. In effect, this change would impact the first stage returns.

The estimators $\widehat{\gamma}_{31}, \widehat{\gamma}_{21}$, and $\widehat{\gamma}_{11}$ were negative, with low significance level. The estimator $\hat{\delta}_{31}$ in the conditional variance equation was also negative and less than zero. This out come implied that the second stage conditional variance was $1.00\left(\widehat{\delta}_{01}+\widehat{\delta}_{11}+\widehat{\delta}_{21}+\widehat{\delta}_{31}\right)$. These results together implied that money supply variance returns, which ranged from 14.34 to 14.57 (Fig. 2), had a negative relationship with credit availability. Therefore, these results supported the implication that if the interbank call interest rate rises, demand for

Table 4 Second stage V-IGARCH(1,1) regression model (Equation 3)

\begin{tabular}{|c|c|}
\hline Estimators & Estimates \\
\hline$\overline{\hat{\gamma}_{01}}$ & $\begin{array}{l}13.4314^{*} \\
(0.0000)\end{array}$ \\
\hline$\hat{\gamma}_{11}$ & $\begin{array}{l}-0.0003 \\
(0.3743)\end{array}$ \\
\hline$\hat{\gamma}_{21}$ & $\begin{array}{l}-0.0017^{* *} \\
(0.0559)\end{array}$ \\
\hline$\hat{\gamma}_{31}$ & $\begin{array}{l}-0.00001 \\
(0.4695)\end{array}$ \\
\hline$\hat{\gamma}_{41}$ & $\begin{array}{l}0.1202^{*} \\
(0.0000)\end{array}$ \\
\hline$\hat{\gamma}_{511}$ & $\begin{array}{l}0.1289^{*} \\
(0.0000)\end{array}$ \\
\hline$\hat{\gamma}_{512}$ & $\begin{array}{l}0.1299^{*} \\
(0.0000)\end{array}$ \\
\hline$\hat{Y}_{513}$ & $\begin{array}{l}0.2368^{*} \\
(0.0000)\end{array}$ \\
\hline$\hat{\delta}_{01}$ & $\begin{array}{l}0.000003^{*} \\
(0.0000)\end{array}$ \\
\hline$\hat{\delta}_{11}$ & $\begin{array}{l}1.0000^{*} \\
(0.0000)\end{array}$ \\
\hline$\hat{\delta}_{21}$ & $\begin{array}{l}-0.000000^{*} \\
(0.0000)\end{array}$ \\
\hline$\hat{\delta}_{31}$ & $\begin{array}{l}-0.000001^{* *} \\
(0.1432)\end{array}$ \\
\hline Log-Likelihood & 2156.2286 \\
\hline
\end{tabular}

Note:* $\left.{ }^{* *}\right)$ Significant at $0.01(<0.01)$ level. The second stage V-IGARCH $(1,1)$ estimation considers NSE daily data from December 02, 2002, to November 30, 2004. Mean and conditional variance equations are,

$M_{3 t}=\hat{\gamma}_{01}+\hat{\gamma}_{11} \Delta \widehat{u}_{t-1}+\hat{\gamma}_{21} \Delta \widehat{u}_{t-2}+\hat{\gamma}_{31} \Delta w_{t-1}+\hat{\gamma}_{41} T_{p t}+\hat{\gamma}_{51} \sum_{i=1}^{3} D_{i}+\varepsilon_{m 3 t}$
$h_{1 t}=\hat{\delta}_{01}+\hat{\delta}_{11} \hat{\varepsilon}_{m 3 t-1}^{2}+\hat{\delta}_{21} h_{1 t-1}+\hat{\delta}_{31} \Delta w_{t-1}^{2}$

where, $M_{3 t}=$ total money supply, $T_{p t}=$ trading prices, and $D_{i}=$ dummy variables = time of submission of limit orders.

Dummy variables $=D_{1}$ is the initial period of the Nifty trading, $D_{2}$ is in between the initial and the last periods of trading, and $D_{3}$ is the last period of the Nifty trading. $\Delta \widehat{u}_{t-1}, \Delta \widehat{u}_{t-2}, \Delta w_{t-1}$, and $\Delta w_{t-1}^{2}=$ First and second differenced residuals and first differenced credit availability dummy values are derived from the first stage V-IGARCH $(1,1)$ estimation. The results indicate that there is a negative effect of total money supply on returns through lower credit availability positions 


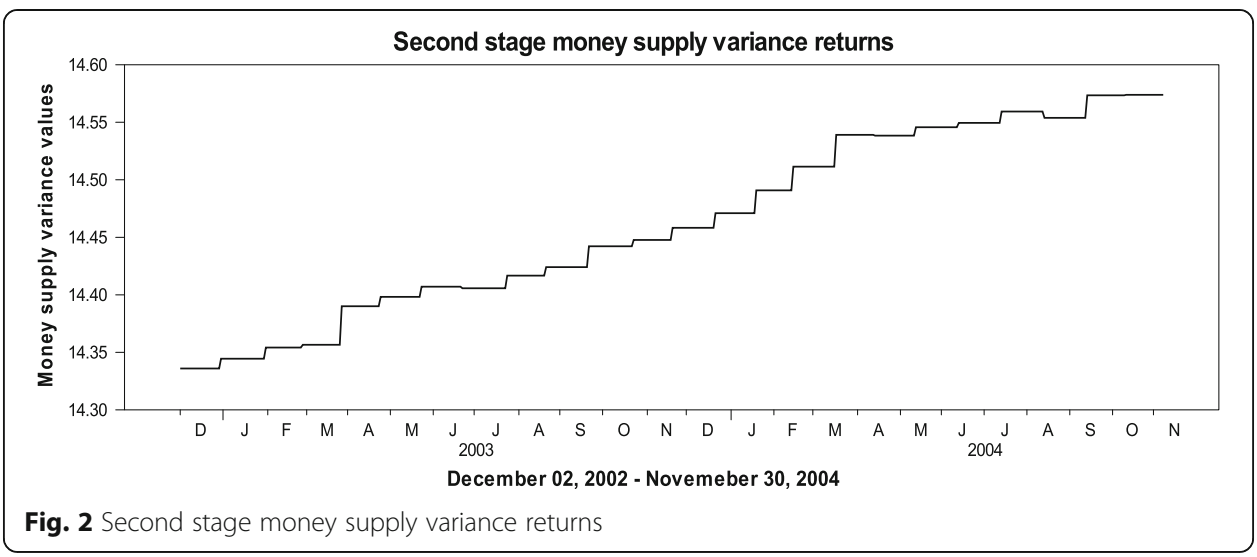

financial resources will fall, then the volume of call money will fall, and the money supply will be underutilized. Therefore, lending to banks, depository participants, and other financial institutions will fall, and vice-versa. Since the trading margin has a direct relationship with the call interest rate, this financing rate should be at an appropriate level, so that the availability of resources for reinvestment in Nifty Futures trading will be ensured.

Table 5 shows that significant estimated slope coefficients $\widehat{\gamma}_{521}, \widehat{\gamma}_{522}$, and $\widehat{\gamma}_{523}$ were negative. These results implied that if the trading hours increase by $1 \%$ of each $1 / 3$ of the total trading time-period, on average, the number of market lots will change by about $-2.4496 \%,-1.4117 \%$, and $-1.4714 \%$ respectively. This finding showed that the number of market lots had a significant negative effect on the first stage returns in all trading hours. Therefore, the tick-value-size ratio had a negative effect on these first stage returns, because if the use of market lots is inefficient then the incentive for investment in the Nifty Futures market will be lower.

Again, inefficiencies regarding market lots caused inefficient creation of tick value in relation to tick size, and thus inefficient price discreteness. This discreteness has an important role in Nifty Futures pricing. Since price discreteness was shown empirically to be inefficient, its role in Nifty Futures trading was also inefficient. Therefore, the study could conclude that price discreteness negatively affects the first stage returns through the inefficient number of Nifty market lots.

Table 5 demonstrates that the significant estimated slope coefficient $\widehat{\gamma}_{42}$ was positive. This result implied that if the risk-neutral trading price increases by $1 \%$, on average, the number of market lots will increase by about $2.3271 \%$. This activity will affect first stage returns positively. Therefore, the results implied that there was a positive relationship between the number of market lots and the first stage returns.

Estimators $\widehat{\gamma}_{22}$ and $\widehat{\gamma}_{12}$ were negative, with lower significance levels. This means that other exogenous miscellaneous factors negatively affected the number of market lots traded. The estimator $\widehat{\gamma}_{32}$ was positive but insignificant. This study concluded that credit availability had an insignificant but positive impact on the number of market lots, and thus on first stage returns.

The estimator $\widehat{\delta}_{32}$ in the conditional variance equation was positive, but with a lower significance level. This implied that the second stage conditional variance was 1.05 
Table 5 Second stage V-IGARCH(1,1) regression model (Equation 4)

\begin{tabular}{|c|c|}
\hline Estimators & Estimates \\
\hline$\hat{Y}_{02}$ & $\begin{array}{l}-4.0502^{*} \\
(0.0000)\end{array}$ \\
\hline$\hat{\gamma}_{12}$ & $\begin{array}{l}-0.1917^{* *} \\
(0.0424)\end{array}$ \\
\hline$\hat{\gamma}_{22}$ & $\begin{array}{l}-0.2083^{* *} \\
(0.0435)\end{array}$ \\
\hline$\hat{\gamma}_{32}$ & $\begin{array}{l}0.0084 \\
(0.3176)\end{array}$ \\
\hline$\hat{\gamma}_{42}$ & $\begin{array}{l}2.3271^{*} \\
(0.0000)\end{array}$ \\
\hline$\hat{\gamma}_{521}$ & $\begin{array}{l}-2.4496^{*} \\
(0.0000)\end{array}$ \\
\hline$\hat{\gamma}_{522}$ & $\begin{array}{l}-1.4117^{* *} \\
(0.0167)\end{array}$ \\
\hline$\hat{\gamma}_{523}$ & $\begin{array}{l}-1.4714^{* *} \\
(0.0138)\end{array}$ \\
\hline$\hat{\delta}_{02}$ & $\begin{array}{l}0.0390^{* *} \\
(0.0057)\end{array}$ \\
\hline$\hat{\delta}_{12}$ & $\begin{array}{l}0.8421^{*} \\
(0.0000)\end{array}$ \\
\hline$\hat{\delta}_{22}$ & $\begin{array}{l}0.1579^{* *} \\
(0.1692)\end{array}$ \\
\hline$\hat{\delta}_{32}$ & $\begin{array}{l}0.0082^{* *} \\
(0.2680)\end{array}$ \\
\hline Log-Likelihood & 266.8531 \\
\hline
\end{tabular}

Note:* $\left.{ }^{* *}\right)$ Significant at $0.01(<0.01)$ level. The second stage V-IGARCH $(1,1)$ estimation considers NSE daily data from December 02, 2002, to November 30, 2004. Mean and conditional variance equations are,

$M_{l t}=\hat{\gamma}_{02}+\hat{\gamma}_{12} \Delta \widehat{u}_{t-1}+\hat{\gamma}_{22} \Delta \widehat{u}_{t-2}+\hat{\gamma}_{32} \Delta w_{t-1}+\hat{\gamma}_{42} T_{p t}+\hat{\gamma}_{52} \sum_{i=1}^{3} D_{i}+\varepsilon_{m i t}$

$h_{2 t}=\hat{\delta}_{02}+\hat{\delta}_{12} \hat{\varepsilon}_{\text {mit-1 }}^{2}+\hat{\delta}_{22} h_{2 t-1}+\hat{\delta}_{32} \Delta w_{t-1}^{2}$

where, $M_{l t}=$ the number of market lots, $T_{p t}=$ trading prices, and $D_{i}=$ dummy variables = time of submission of limit orders. Dummy $D_{1}$ is the initial period of the Nifty trading, $D_{2}$ is in between the initial and the last periods of trading, and $D_{3}$ is the last period of the Nifty trading. $\Delta \widehat{u}_{t-1}, \Delta \widehat{u}_{t-2}, \Delta w_{t-1}$, and $\Delta w_{t-1}^{2}=$ first and second differenced residuals and first differenced credit availability dummy values are derived from the first stage V-IGARCH $(1,1)$ estimation. This result indicates that there is an inverse relationship between the number of market lots and risk-neutral trading price in all trading hours causes the returns as inefficient. Since the number of market lots determines the tick value in relation to tick size and hence price discreteness has negative effects on returns

$\left(\widehat{\delta}_{02}+\widehat{\delta}_{12}+\widehat{\delta}_{22}+\widehat{\delta}_{32}\right)$, where the number of market lots variance returns ranged from 8.80 to 12.79 (Fig. 3). These results implied that the number of market lots, and thus price-discreteness, had a lower negative impact on the first stage returns with lower credit availability.

In Table 6, the significant estimated slope coefficients $\hat{\gamma}_{531}, \hat{\gamma}_{532}$, and $\hat{\gamma}_{533}$ were both negative and positive. That is, if the trading hours increase by $1 \%$ of each $1 / 3$ of the total trading time-period (approximately $1.12 \mathrm{~min}$ ), on average, the impact costs will change by $-0.1027 \%, 0.2324 \%$, and $-0.0278 \%$ respectively. Therefore, impact costs have a significant reduction effect on the first stage returns at the initial and last periods of the Nifty trading hours, as compared with the other trading hours. Surprisingly, these impact costs have positive reduction effects on returns between the initial and last periods of Nifty Futures trading.

Table 6 shows that the significant estimator $\hat{\gamma}_{43}$ was negative. This implies that if the trading prices increase by $1 \%$, on average, impact costs will change by about $-0.3738 \%$, which is more than the effect of most of other independent variables. 


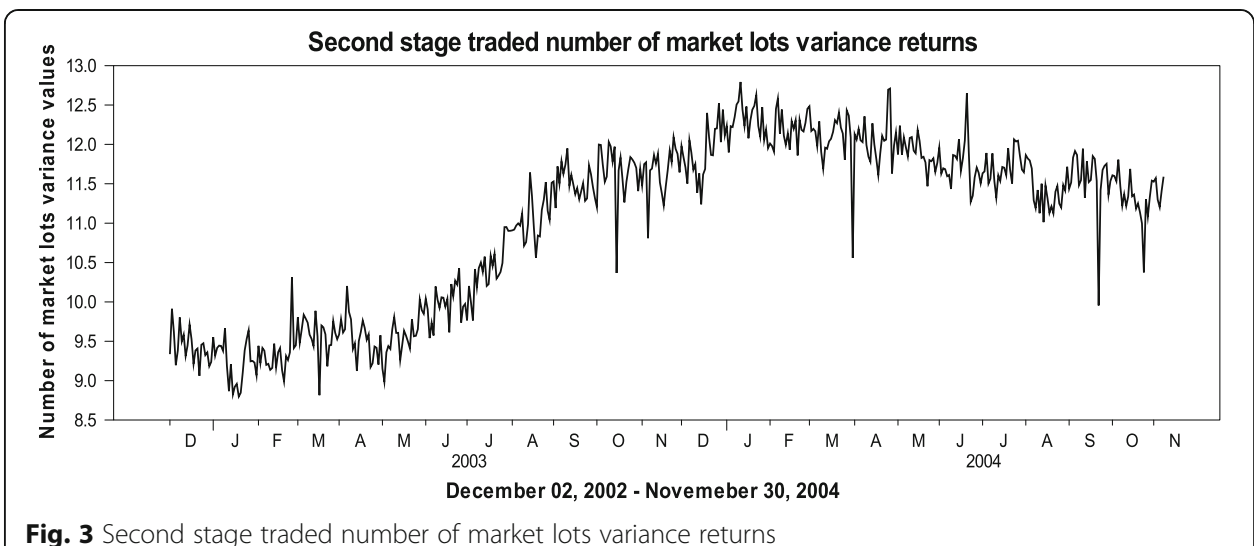

Fig. 3 Second stage traded number of market lots variance returns

Table 6 Second stage V-IGARCH(1,1) regression model (Equation 5)

\begin{tabular}{ll}
\hline Estimators & Estimates \\
\hline$\hat{\gamma}_{03}$ & $-0.3041^{*}$ \\
& $(0.0000)$ \\
$\hat{\gamma}_{13}$ & 0.0021 \\
& $(0.2431)$ \\
$\hat{\gamma}_{23}$ & 0.0015 \\
& $(0.3027)$ \\
$\hat{\gamma}_{33}$ & -0.0003 \\
& $(0.3708)$ \\
$\hat{\gamma}_{43}$ & $-0.3738^{*}$ \\
& $(0.0000)$ \\
$\hat{\gamma}_{531}$ & $-0.1027^{*}$ \\
$\hat{\gamma}_{532}$ & $(0.0000)$ \\
$\hat{\gamma}_{533}$ & $0.2324^{*}$ \\
$\hat{\delta}_{03}$ & $(0.0000)$ \\
$\hat{\delta}_{13}$ & $-0.0278^{*}$ \\
$\hat{\delta}_{23}$ & $(0.0000)$ \\
$\hat{\delta}_{33}$ & $-0.000006^{* *}$ \\
Log-Likelihood & $(0.0116)$ \\
$\hat{y}^{*}$ & $1.0000^{*}$ \\
& $(0.0000)$ \\
& $-0.000000^{*}$ \\
& $(0.0000)$ \\
& $0.0005^{*}$ \\
& $(0.0000)$ \\
& 1089.7317 \\
\hline
\end{tabular}

Note:* $\left.{ }^{* *}\right)$ Significant at $0.01(<0.01)$ level. The second stage V-IGARCH $(1,1)$ estimation considers NSE daily data from December 02, 2002, to November 30, 2004. Mean and conditional variance equations are,

$C_{t}=\hat{\gamma}_{03}+\hat{\gamma}_{13} \Delta \widehat{u}_{t-1}+\hat{\gamma}_{23} \Delta \widehat{u}_{t-2}+\hat{\gamma}_{33} \Delta w_{t-1}+\hat{\gamma}_{43} T_{p t}+\hat{\gamma}_{53} \sum_{i=1}^{3} D_{i}+\varepsilon_{c t}$
$h_{3 t}=\hat{\delta}_{03}+\delta_{13} \hat{\varepsilon}_{t t-1}^{2}+\hat{\delta}_{23} h_{1 t-1}+\delta_{33} \Delta w_{t-1}^{2}$

where, $C_{t}=$ total money supply, $T_{p t}=$ trading prices, and $D_{i}=$ dummy variables $=$ time of submission of limit orders. Dummy $D_{1}$ is the initial period of th e Nifty trading, $D_{2}$ is in between the initial and the last periods of trading, and $D_{3}$ is the last period of the Nifty trading. $\Delta \widehat{u}_{t-1}, \Delta \widehat{u}_{t-2}, \Delta w_{t-1}$, and $\Delta w_{t-1}^{2}=$ first and second differenced residuals and first differenced credit availability dummy values are derived from the first stage V-IGARCH $(1,1)$ estimation. This result indicates that impact costs are higher in the entire trading time-period (trading hours from 09:55 IST to15:30 IST) of submission of limit orders and hence reduction effects on returns exist 
In essence, this will affect first stage returns. Therefore, changes in impact costs was more due to changes in trading prices than changes of other independent variables in the model. This finding explains about the symmetric informational nature of $T_{p t}$.

The estimated slope coefficients $\hat{\gamma}_{13}, \hat{\gamma}_{23}$, and $\hat{\gamma}_{33}$ were close to zero at 0.0021 , 0.0015 , and -0.0003 respectively with lower significance levels. This finding implied that other factors, including the credit availability of market participants, had negligible effects on impact costs. One can say that credit availability had a negligible effect on impact costs when efficient money supply management existed through the interbank call interest rate. Thus, efficient effects of impact costs on returns existed. The estimator $\hat{\delta}_{33}$ in the variance equation was positive, but with a lower value by 0.0005 . Thus, the second stage conditional variance was $1.00\left(\hat{\delta}_{03}+\hat{\delta}_{13}+\hat{\delta}_{23}+\hat{\delta}_{33}\right)$, where the impact cost variance returns ranged from -2.66 to -1.77 (Fig. 4 ). The estimator $\hat{\delta}_{33}$ demonstrated through the variance returns that impact costs had a negligible relationship with credit availability. Therefore, impact costs had negative effects on first stage returns because of inefficient hedging in the Nifty derivatives market. The risk reduction in securities was less, despite the use of derivatives.

From both stages of empirical estimations, it was observed that independent variables caused dependent variables and hence effects on returns. Both variables in this two-stage V-IGARCH $(1,1)$ model were stationary in nature. In the first stage, it was observed that returns and trading margins, as well as credit availability, were cointegrated, thereby indicating a long-term relationship between them. In the first stage of the V-IGARCH $(1,1)$ model, heteroscedasticity with the mean returns through residuals was observed, where the estimated coefficients were negative. This finding indicated that maximizing returns requires efficient use of trading margins as well as availability of credit positions. The first stage estimation showed that returns decreased by $2.2663 \%$ as a consequence of non-realization of efficient trading margins and effective credit availability positions. This was the result of endogenous and exogenous conditional probabilistic values, which were estimated with the second stage V-IGARCH $(1,1)$ regression models.

From the second stage regression estimation, it was observed that trading prices and total money supply were directly related, and thus had direct effects on returns. The total money supply increased gradually until the last trading hour. In the conditional

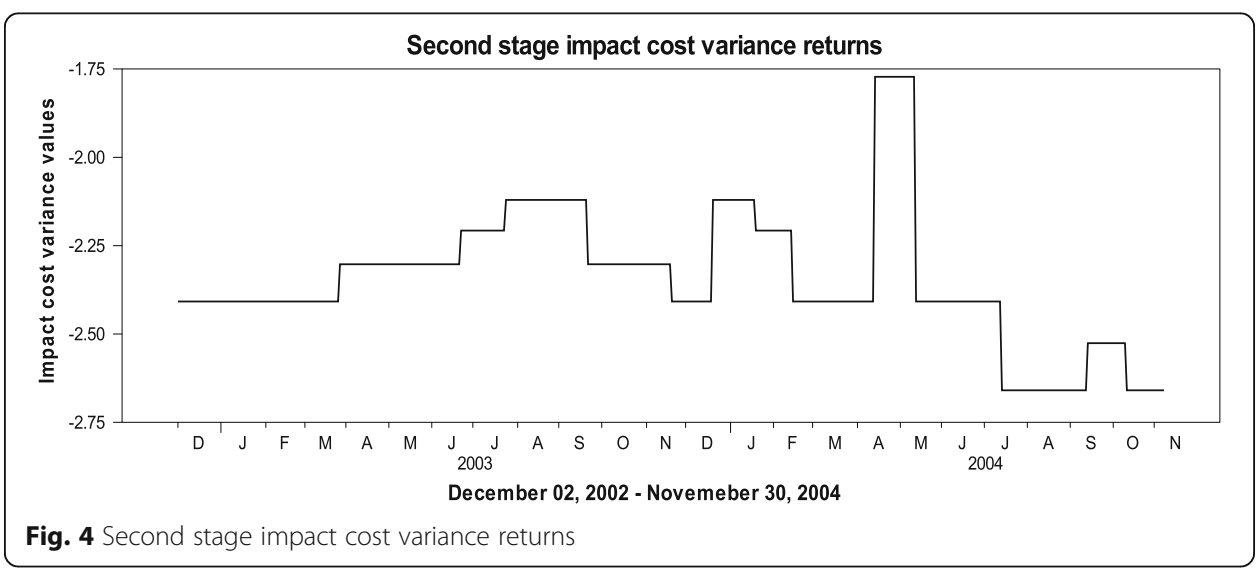


variance equation, total money supply was related negatively to the availability of credit for market participants. Under these circumstances, the efficient interbank call interest rate was necessary to maintain the trading margin. In effect, efficient Nifty returns would be achieved.

The tick value is the product of tick size and contract size. Contract size is equal to the product of the base Nifty price and the number of market lots traded. Here, the Nifty base value was constant and the tick size was constant. The tick-value-size ratio, and hence price discreteness, depended on the number of market lots (market depth). Therefore, price discreteness and its optimality were evaluated through the number of market lots. This stage of estimation observed that trading prices and the number of market lots were positively related. However, with negative credit availability, the number of market lots had negative impact on returns during all trading hours. Therefore, price discreteness had a negative impact on returns.

Impact costs were negatively related with each of the Nifty trading hours. Impact costs were also negatively related with trading prices. Credit availability had a lower effect on impact costs. Therefore, impact costs negatively affected first stage returns. This finding implied that trading risks were not minimized by hedging positions. Therefore, this study suggested that with more credit availability through efficient money supply management, impact costs will have a positive impact on the first stage returns. Thus, efficient returns would be achieved.

\section{Conclusion}

This study rejected the null-hypothesis and concluded that trading margins, credit availability, and price discreteness affect the variance of returns in the Indian futures markets. The study found that market participation was inadequate as a result of endogenous and exogenous conditional probabilistic reasons. Efficient trading margins and effective credit availability positions were not realized. Price discreteness had a negative impact on returns, as trading prices and credit availability in each of the trading hours were inversely related. Trading risks, and hence losses, were not minimized by hedging positions (Prasanna Kumar and Supriya, 2014). The maximum likelihood estimator $\widehat{\beta}_{1}$ was $|-0.1117|$; it was less than one but not equal to zero. Alternatively, its absolute value represented elasticity of returns, which explained magnitude rather than direction of changes in returns. As a result, the monopoly power in the Nifty market was 8.9526 (i.e., 1 / |-0.1117|). Given this monopoly power, returns were less elastic with respect to the existing trading margins, financial resources, and market microstructure (price discreteness) that were available for reinvestment.

Given the above findings, one can conclude that before investing in derivatives (index futures), market investors should evaluate trading margins, credit availability positions, and price discreteness. The above empirical results strongly suggest that trading margins, credit availability position, and price discreteness are decision-making market signals. Through these signals, investors will be able to gain essential market knowledge and participate accordingly in trading for efficient returns. Future research will focus on the efficiency of other market micro structures with regard to speculation and arbitration. 


\section{Acknowledgements}

This research article is part of the ICSSR (New Delhi) project 'Market Making and Creditworthiness for S \& P CNX Nifty Futures: A Signalling Equilibrium Approach, 2008'. I thank Dr. Inder Sekhar Yadav, Institute of Economic Growth, New Delhi for his necessary help on providing some of related literatures. I thank anonymous reviewers for their valuable suggestions to improve this research article.

Funding

Southwestern University of Finance and Economics.

\section{Competing interests}

There are no competing interests.

Received: 6 August 2016 Accepted: 2 September 2017

Published online: 14 October 2017

\section{References}

Badhani KN (2007) Expiration-day effects of derivatives on price, volume and volatility of cash segment of stock market. Finance India 21(3):897-905

Bali R, Hite GL (1998) Ex-dividend day stock price behaviour: discreteness or tax-induced clienteles? J Financ Econ 47(2): 127-159

Barik PK, Supriya MV (2005) Signalling in Indian futures market. The ICFAI Journal of Applied Finance 11(4):13-30 Barik PK, Supriya MV (2007) Signalling in S \& P CNX nifty futures market at NSE, India. Decision 34(1):183-212

Barik PK, Supriya MV (2008) Signaling in CNX nifty futures: a perceptual approach. Asia-Pacific Business Review 4(3):82-86

Barik PK, Supriya MV (2009) Market making signals for CNX nifty futures. International Review of Business Research Papers 5(1):184-190

Black SE, Strahan PE (2002) Entrepreneurship and bank credit availability. J Financ 57(6):2807-2833

Bollerslev T (1986) Generalized autoregressive conditional heteroskedasticity. J Econ 31(3):307-327

Bollerslev T (1987) A conditionally heteroskedastic time series model for speculative prices and rates of ret urn. Rev Econ Stat 69(3):542-547

Bollerslev T, Engle RF, Wooldridge JM (1988) A capital-asset pricing model with time-varying covariances. J Polit Econ 96(1):116-131

Dickey DA, Fuller WA (1981) Likelihood ratio statistics for autoregressive time series with a unit root. Econometrica 49(4):1057-1072

Engle RF, Granger CWJ (1987) Co-integration and error correction: representation, estimation, and testing. Econometrica 55(2):251-276

Frank M, Jagannathan R (1998) Why do stock prices drop by less than the value of the dividend? Evidence from a country without taxes. J Financ Econ 47(2):161-188

Graham JR, Michaely R, Roberts MR (2003) Do price discreteness and transaction costs affect stock returns? Comparing ex-dividend pricing before and after decimalization. J Financ 58(6):2611-2636

Granger CWJ (1969) Investigating causal relations by econometric models and cross-spectral methods. Econometrica 37(3):424-438

Hiraki T, Maberly ED, Takezawa N (1995) The information content of end-of-the-day index futures ret urn: international evidence from the Osaka Nikkei 225 futures contract. Journal of Banking and Finance 19(5):921-936

Jakob K, Ma T (2004) Tick size, NYSE rule 118 and ex-dividend day stock price behaviour. J Financ Econ 72(3):605-625

Mankiw NG (2003) Macroeconomics. Worth Publishers, New York

Panda C (2008) Do interest rate matter for stock market? Econ Polit Wkly 43(17):107-115

Prasanna Kumar B (2011) Social banking with CSP and CFP relation in India: an empirical analysis. Asia-Pacific Business Review 7(4):125-135

Prasanna Kumar B, Supriya MV (2014) Evidence on hedging effectiveness in Indian derivatives market. Asia-Pacific Finan Markets 21(2):121-13

Tassel EV (2002) Signal jamming in new credit markets. J Money, Credit, Bank 34(2):469-490

Yuan K (2005) Asymmetric price movements and borrowing constraints: a rational expectations equilibrium model of crises, contagion, and confusion. J Financ 60(1):379-411

\section{Submit your manuscript to a SpringerOpen ${ }^{\circ}$} journal and benefit from:

- Convenient online submission

- Rigorous peer review

- Open access: articles freely available online

High visibility within the field

Retaining the copyright to your article

Submit your next manuscript at $>$ springeropen.com 